\title{
La burocracia norteamericana y el cambio de Política Exterior. La transición a la política de Derechos Humanos de Carter hacia la Argentina (1976-1977) ${ }^{1}$
}

\section{American bureaucracy and foreign policy change. The transition to The U.S. human rights policy to Argentina under the Carter administration (1976-1977)}

\author{
Alejandro Avenburg ${ }^{2}$
}

Resumen: Este trabajo analiza el rol del Departamento de Estado y de la Embajada norteamericana en Buenos Aires en el proceso de implementación de la política de Derechos Humanos de la administración Carter hacia la Argentina. Diversos trabajos han destacado la resistencia de dichos sectores a la implementación de esta política. Utilizando documentos desclasificados del Departamento de Estado, analizamos aquí dos canales de implementación: el de las sanciones económicas y militares y el de los contactos privados bilaterales. Argumentamos que si bien estos actores se opusieron a la implementación de sanciones, en el canal diplomático bilateral hubo un consistente mensaje abogando por la implementación de medidas que buscaban mejoras en la situación de los Derechos Humanos en el país.

Palabras clave: Derechos Humanos, Burocracia, Carter, Argentina.

Abstract: This article analyzes the role of the State Department and of the U.S. Embassy in Buenos Aires during the implementation of Jimmy Carter's human rights policy towards Argentina. Prior research has emphasized the reluctance of those sectors to implement this policy change. Using declassified documents from the U.S. State Department, we analyze two channels of implementation of this policy: economic and military sanctions, and private bilateral contacts. We argue that, while those actors opposed U.S. sanctions against Argentina, in private bilateral meetings they consistently supported measures that sought to improve the situation of human rights in Argentina.

Key Words: Human Rights, Bureaucracy, Carter, Argentina

\footnotetext{
${ }^{1}$ Recibido: 22/09/2017. Aceptado: 26/03/2018

${ }^{2}$ Doctor en Ciencia Política por la Universidad de Boston y actualmente becario post-doctoral de Conicet con sede en la Universidad Nacional de San Martín. Su investigación se centra en dos áreas principales: corrupción y accountability y Derechos Humanos. Contacto: avenburg@bu.edu; aleavenburg@gmail.com
} 


\section{Introducción}

La asunción de Jimmy Carter como presidente de los Estados Unidos en enero de 1977 trajo un importante cambio en las concepciones que guiaban la política exterior norteamericana, que tradicionalmente privilegiaban la lucha contra el comunismo por sobre la promoción de valores. Carter propuso poner fin al apoyo de Estados Unidos a los regímenes responsables de violaciones a los Derechos Humanos, incluyendo a los tradicionales aliados, como las dictaduras militares latinoamericanas. Para ello, la Argentina fue elegida como un caso testigo: se trataba de un país relativamente grande y por lo tanto visible pero que carecía de interés estratégico para los Estados Unidos (Escudé, 1991).

La implementación de esta política estuvo a cargo de dos oficinas pertenecientes al Departamento de Estado. La primera de éstas, el Área de Repúblicas Americanas (de aquí en adelante ARA), era la oficina regional encargada de las relaciones con los países de América Latina y el Caribe. Su orientación la volcaba a una activa defensa de la tradicional política de alianzas con los gobiernos anti-comunistas. El ARA, hasta la llegada de Carter, había sido la oficina que más peso tenía en las decisiones respecto a América Latina. (Schoultz, 1981). La segunda de ellas, la Oficina de Derechos Humanos y Asuntos Humanitarios (de aquí en adelante HA), había sido creada por el Congreso en 1973 con el objetivo de vigilar el respeto de los Derechos Humanos en el mundo y promover su incorporación a la agenda de la política exterior norteamericana. Un tercer actor fundamental eran los propios diplomáticos de las Embajadas norteamericanas en el mundo, quienes estaban a cargo de implementar en el terreno las decisiones tomadas en Washington.

En este trabajo nos proponemos analizar la implementación por parte de la burocracia del ARA y de los diplomáticos de la Embajada de la política de Derechos Humanos hacia la Argentina. En particular, nos centraremos en el período de cambio de la orientación de la política exterior (1976-1977). El trabajo se encuadra en una amplia literatura que destaca el rol de las pujas inter-burocráticas y sus efectos sobre la implementación de la política exterior (Destler, 1974; Allison y Zelikow, 1999; Halperin y Clapp, 2007). Dicha literatura estudia las relaciones inter-burocráticas, enfatizando el rol de los propios intereses y orientaciones de cada una de las agencias; intereses y orientaciones que tienden a persistir en el tiempo. Consecuentemente, era esperable que tanto el ARA como los diplomáticos de la Embajada se opusieran al cambio de orientación en la política exterior de Carter. Dichas resistencias fueron analizadas en numerosos estudios sobre el tema (Sikkink, 2004a; Sikkink, 2004b; Schmidli, 2011; Escudé y Cisneros, 2000).

Este trabajo presenta una contribución a esta literatura estableciendo una distinción entre la implementación de la política de Derechos Humanos mediante sanciones económicas y militares y su implementación a través de una diplomacia silenciosa, entendiendo a esta como una forma de promover un objetivo - en este caso el respeto a los Derechos Humanos - a través de discusiones privadas y confidenciales, por fuera del escrutinio público (Forsythe, 2012: 199)

A partir de inicios de la década del '70, nueva legislación promovida por varios legisladores demócratas determinaba una serie de sanciones económicas y militares a los países en los que ocurrieran sistemáticas violaciones los Derechos Humanos. Ante la posibilidad de críticas y denuncias públicas por parte de los sectores del Departamento de Estado más comprometidos con los Derechos Humanos, sectores del ARA favorecie- 
ron el recurso de la diplomacia silenciosa como modo de influir sobre el comportamiento de la Argentina sin necesidad de generar tensiones en las relaciones diplomáticas.

Utilizando documentos desclasificados del Departamento de Estado (de aquí en adelante SADP) y entrevistas del Archivo de Historial Oral del Instituto de Investigaciones Gino Germani de la Universidad de Buenos Aires (de aquí en adelante AHO), argumentamos que incluso aquellos funcionarios del ARA y de la Embajada que abierta o encubiertamente mostraron rechazo a la implementación de sanciones, en sus contactos bilaterales con miembros del gobierno argentino buscaron promover medidas a favor de un mayor respeto por los Derechos Humanos como medio para evitar que el Congreso endureciera su postura. De este modo, abogaron por medidas puntuales como la publicación de las listas de detenidos por el gobierno para evitar que el Congreso sancionara a la Argentina. A diferencia de los mensajes de apoyo a la dictadura del secretario de Estado Kissinger (Sikkink, 2004a), su mensaje fue claro e inequívoco, explicando que la preocupación por los Derechos Humanos era un foco central de la nueva política exterior norteamericana.

En la primera parte del trabajo, hacemos un breve repaso de la literatura sobre política burocrática y su incidencia en la implementación de la política exterior y describimos cómo otros autores han analizado las relaciones entre la Argentina y los Estados Unidos durante la administración Carter. En la segunda sección, describimos los cambios en la legislación del Congreso que dieron origen a la política de Derechos Humanos. Seguidamente, mostramos cómo dicha política se aplicó en diversos casos latinoamericanos. En la cuarta sección, analizamos los cables internos de funcionarios del ARA y sus contactos con miembros del gobierno militar argentino entre fines de 1976 y comienzos de 1977. Luego, nos enfocamos en los informes internos del Departamento de Estado y la posición del ARA frente a la posibilidad de que se impusieran sanciones militares a la Argentina. En la sexta sección, nos centramos en los contactos bilaterales durante los inicios de la administración Carter. Seguidamente, analizamos el lugar que adoptaron los diversos actores burocráticos durante los primeros tiempos de la administración Carter. Finalmente, exponemos las conclusiones, analizando los dos canales de implementación de la política de Derechos Humanos durante este período y el rol que tuvieron los diversos actores.

\section{Marco teórico y antecedentes}

Numerosos estudios han analizado el rol de los intereses burocráticos en la formulación y ejecución de la política exterior (Allison y Zelikow, 1999; Halperin y Clapp, 2007). Estos estudios destacan la fuerte incidencia de las preferencias de las diversas agencias en la orientación política resultante, así como la persistencia de dichos intereses a lo largo del tiempo. En particular, cuando una administración busca modificar la agenda, las agencias burocráticas cuyas prioridades son relegadas tienden a resistir el cambio.

Siguiendo estas perspectivas, era esperable que la burocracia tradicionalmente encargada de llevar las relaciones con América Latina, el ARA, se opusiera a otorgar un mayor énfasis a la promoción de valores en la política exterior. Esta nueva orientación se oponía a la forma en que se venía ejerciendo la diplomacia con los países de América Latina, una diplomacia basada en el mantenimiento de buenas relaciones en la medida 
en que los gobiernos tuvieran una orientación pro-norteamericana y anti-comunista. Tal como afirma Schoultz (1981), la propia función de los diplomáticos consiste en que las relaciones entre su país y el país huésped se desarrollen fluidamente: la política de Derechos Humanos se presentaba como un factor perturbador.

Varios estudios que han investigado este caso en particular han destacado los conflictos entre el ARA y HA y las resistencias de aquél en la implementación de la política de Carter (Sikkink, 2004a; Sikkink, 2004b; Schmidli, 2011; Escudé y Cisneros, 2000). Las sanciones económicas y militares eran uno de los principales instrumentos que la legislación del Congreso había previsto para lidiar con gobiernos represivos (Apodaca 2005). De ahí que uno de los principales campos de disputa entre el ARA y HA fuera en qué medida resultaba apropiado sancionar a dictaduras que tradicionalmente habían sido aliadas de los Estados Unidos (Sikkink, 2004a; Sikkink, 2004b; Schmidli, 2011). Incluso para los propios sectores que sí deseaban impulsar el cambio en la política exterior, no resultaba sencillo determinar qué instrumentos utilizar para impulsar un cambio en las prácticas domésticas de otros Estados (Schmitz y Walker, 2004; Da Vinha, 2014).

Había, sin embargo, un segundo canal en el que se implementaba la política exterior de Washington: el de las conversaciones directas y mensajes transmitidos a las autoridades argentinas. En este sentido, Schoultz (1981) ha relativizado la oposición del ARA a la política de Derechos Humanos, al afirmar que dicha oposición no era total, sino solamente un rechazo a utilizar las sanciones como principal instrumento. En la opinión de varios altos funcionarios del ARA, la capacidad de los Estados Unidos de influir sobre otros gobiernos y modificar sus prácticas represivas dependía, en buena medida, de que ambos gobiernos preservaran buenas relaciones diplomáticas (Schoultz, 1981: 120-121). Tal como explica este autor, la preferencia del ARA por la diplomacia silenciosa se entiende, en buena medida, por la misión de este organismo encargado del mantenimiento de buenas relaciones.

Ese temprano trabajo de Schoultz se basaba en entrevistas con encargados de implementar políticas, ya que al momento aún no se contaba con documentos desclasificados con las cuales analizar el proceso de implementación, más allá de los testimonios orales. Contra esta opinión, Sikkink (2004b), utilizando documentos desclasificados, destaca "señales contradictorias" en la diplomacia silenciosa. Mientras que el embajador norteamericano en la argentina Robert Hill intentaba convencer a los miembros de la Junta Militar que la preocupación del gobierno norteamericano por los derechos humanos era seria, el secretario de Estado Henry Kissinger manifestaba su apoyo en privado al canciller argentino César Guzzetti limitándose a aconsejarle que terminaran con la represión ilegal antes del cambio de administración. Cabe destacar que el trabajo de Sikkink analiza estas señales contradictorias durante la administración Ford, con Henry Kissinger como secretario de Estado, en una etapa anterior a la victoria de Carter en las elecciones, cuando aún no quedaba claro que el interés del Congreso por los Derechos Humanos se trasladaría al Ejecutivo.

Este trabajo recupera esa discusión analizando los dos canales de implementación de la política de Derechos Humanos, sanciones y diplomacia silenciosa, centrándose en el período de cambio de política exterior. Una vez que Carter obtuvo la victoria en las elecciones, y aún antes de la asunción del candidato demócrata, la burocracia ya se preparaba para el cambio. Los documentos analizados muestran que en este período, el ARA incorporó la agenda de Carter, pero aconsejando ejercer la diplomacia silenciosa. Para 
ello, solicitaron activamente a los miembros del gobierno militar que terminaran con la represión ilegal y promovieron medidas que ayudaran a la plena restauración de los derechos constitucionales, a diferencia de los mensajes de apoyo que Kissinger les había dado hacia mediados de 1976 (Sikkink, 2004a; Sikkink, 2004b). En buena medida, estos funcionarios se orientaban a lograr mejoras puntuales en el área, que luego pudieran utilizar para impedir que la Casa Blanca aplicara sanciones. En ese sentido, la diplomacia silenciosa no era más que un medio para mantener el tradicional objetivo burocrático de preservar buenas relaciones. La novedad del cambio en las relaciones de poder al interior de los Estados Unidos - con un Ejecutivo dispuesto a aplicar las sanciones que proponía el Congreso - obligó a la burocracia del ARA y a diplomáticos de la Embajada a evitar estas señales contradictorias y emitir un claro mensaje al gobierno argentino.

\section{Los cambios en la legislación del Congreso norteamericano en los años '70}

A comienzos de la década del '70, el Congreso comenzó a incrementar su preocupación por los Derechos Humanos y a presionar por que éstos tuvieran un rol mayor en la política exterior de los Estados Unidos, un cambio asociado con el trauma de la guerra de Vietnam y con el caso Watergate (Arnson, 1993). Ambos episodios habían convencido a varios congresistas de la necesidad de aumentar la influencia del Legislativo sobre el Ejecutivo en el ejercicio de la política exterior, hacia una dirección más orientada a la promoción de valores ${ }^{3}$. Durante estos años se promulgaron dos enmiendas que serían centrales para la política de Derechos Humanos. La Sección 502B (de la Ley de Ayuda Externa de 1961) de 1974 determinaba la reducción substancial o terminación de la asistencia militar a gobiernos involucrados en grandes violaciones a "Derechos Humanos internacionalmente reconocidos". La enmienda Harkin (Sección 116 de la Ley de Ayuda Externa de 1961) de 1975, determinaba que no se proveería asistencia económica a dichos países, con excepción de los casos en que esa asistencia se destinaba directamente a personas necesitadas.

Estas enmiendas se convirtieron en el núcleo de la política de Carter. Pero el modo en que serían implementadas quedó sujeto a la discusión política. Arnson (1993) destaca que por el modo en que fue diseñada, esta legislación daba un margen de maniobra al Ejecutivo para que la implementara de acuerdo a sus objetivos. No buscaba crear una "política exterior del Congreso", sino orientar al presidente en una determinada dirección. Según la Sección 502B la reducción o eliminación de la asistencia militar a los regímenes represivos podía quedar exceptuada si el presidente consideraba que esa asistencia era vital para los intereses de seguridad de los Estados Unidos. De hecho, durante este período no hubo sanciones a regímenes como el de Corea del Sur o Filipinas, que eran considerados de interés vital para los Estados Unidos.

La cuestión de los Derechos Humanos ocupó un lugar central en la política exterior norteamericana hacia varias dictaduras latinoamericanas. El régimen de Pinochet, en

\footnotetext{
${ }^{3}$ Entre los legisladores más activos en este sentido se encontraban Hubert Humphrey (senador demócrata por el Estado de Minessota), Edward Kennedy (senador demócrata por Massachusetts), Tom Harkin (senador demócrata por el Estado de lowa), Donald Fraser (senador demócrata por Minnessota).
} 
Chile, ya había sido uno de los focos centrales de la preocupación del Congreso desde antes de la llegada de Carter al poder, incluyendo varias sesiones especiales y fuertes sanciones económicas y militares. Así, a comienzos de 1976 el Congreso determinó la suspensión de la ayuda militar y de la venta de armas al régimen de Pinochet. Luego de 1977, las sanciones se endurecieron aún más (Sikkink, 2004b: 125).

La dictadura militar uruguaya fue otro de los focos de preocupación de la administración Carter. Ya a comienzos de 1977 el gobierno norteamericano decidió reducir la asistencia económica a ese país y los delegados norteamericanos se opusieron a doce de los trece pedidos de créditos en los organismos multilaterales por parte de Uruguay entre 1977 y 1980 (Sikkink, 2004b, p. 128).

Las sanciones económicas y militares también se emplearon para promover la democratización. Por ejemplo, en Bolivia, luego de que el general Juan Pareda Asbún liderara un golpe de estado en 1978, el gobierno norteamericano decidió suspender fondos para asistencia militar por un total de 14 millones de dólares hasta que el general Pareda se comprometiera a llamar nuevamente a elecciones (Griesgraber, 1983, p. 215). Poco tiempo después, el general Natusch Busch lideraría un nuevo golpe, en noviembre de 1979, tras lo cual el gobierno norteamericano suspendería el otorgamiento de fondos para la asistencia económica por 22 millones de dólares y fondos para la asistencia militar por un total de 6 millones de dólares. Luego de un nuevo golpe militar - tras un breve interregno democrático - liderado por el general Luis García Meza, en junio de 1980, el gobierno de Carter decidió suspender toda la asistencia militar y económica al país, con excepción de los fondos que se destinaban a ayuda humanitaria, y retiró su embajador del país (Griesgraber, 1983, p. 214-215).

La combinación de una diplomacia silenciosa crítica hacia las prácticas represivas con declaraciones públicas más conciliadoras fue utilizada por Carter en el caso de Nicaragua, previo a la llegada del Sandinismo al poder, en 1979. En este caso, dado que la posibilidad de una revolución era más cercana, la administración Carter utilizó contactos privados para convencer al gobierno de Somoza de la importancia que la administración daba a la cuestión de los Derechos Humanos, mientras que en público la diplomacia norteamericana utilizó un tono mucho más conciliador (Schmitz y Walker, 2004: 138). Esto llevó a numerosas críticas internas en los Estados Unidos, tanto de parte de aquellos sectores que criticaban a Carter por considerar que se estaba abandonando a un aliado en la lucha contra el comunismo, como de aquellos sectores que manifestaban que la administración estaba siendo demasiado contemplativa con un régimen altamente represivo.

Un enfoque similar siguió la administración en su política hacia El Salvador, en donde un gobierno democrático que había llegado al poder de manera fraudulenta ejercía una política fuertemente represiva hacia la oposición (Griesgraber, 1983: 264). Si bien, antes de la llegada del Sandinismo al poder en Nicaragua, la administración tuvo un enfoque más duro hacia el gobierno del presidente Carlos Humberto Romero, luego de la revolución en la vecina Nicaragua, la diplomacia norteamericana decidió dejar de lado su política de sanciones y continuar con la asistencia militar a ese país (Griesgraber, 1983, p. 279). Tal como reconoce Sikkink (2004b, p. 124) en países como Guatemala y El Salvador, en donde las guerrillas insurgentes eran mucho más fuertes, la política exterior de Carter estuvo fuertemente orientada por el enfoque que privilegiaba la seguridad nacional y la lucha contra el comunismo, en especial luego de la revolución Sandinista. 
De ahí la opinión de varios funcionarios del ARA de que la administración de Carter tenía una política de doble estándar, ya que mientras que se sancionaba a la Argentina se mantenía la ayuda a otros regímenes represivos de mayor interés estratégico para los Estados Unidos. (entrevista con Tex Harris, AHO). En ese sentido, Robert Pastor, ex director de Asuntos Latinoamericanos y del Caribe del Consejo de Seguridad Nacional de la administración de Carter, reconoce que la Argentina no era considerado por la administración como un país estratégico. Según Pastor, la perspectiva de la nueva administración era que el desarrollo nuclear argentino no estaba demasiado avanzado y no era por lo tanto preocupante, por eso fijaron su prioridad en los Derechos Humanos por sobre los temas nucleares (entrevista a Robert Pastor, AHO).

La reacción de los militares argentinos tuvo varios elementos centrales. Por un lado, todos los sectores militares habían coordinado una estrategia de desinformación que pretendía mostrar a Videla como un "moderado" que buscaba detener a grupos paramilitares que operaban amparados por militares de "línea dura"4 (Avenburg, 2009a). De esta forma, la dictadura militar argentina buscó evitar las sanciones internacionales que presionaban al régimen militar chileno.

A su vez, diversas facciones militares adoptaron posturas contrapuestas respecto a la política exterior norteamericana. Según Novaro y Avenburg (2009), la orientación de política exterior de las diversas facciones del gobierno militar pueden resumirse en tres grupos. Un primer grupo, liderado por varios comandantes de Cuerpo del Ejército como el general Suárez Mason, el general Menéndez y el general Ramón Díaz Bessone, se inclinaba a adoptar un regionalismo defensivo, promoviendo alianzas con otras dictaduras militares de la región para organizar un frente común contra la política de Carter. Un segundo grupo, liderado por los generales Videla y Viola, quería evitar fricciones diplomáticas con los Estados Unidos y estaba más inclinados a hacer "concesiones tácticas $^{\prime \prime}$ frente a las presiones norteamericanas. Por último, sectores nacionalistas de las tres fuerzas incluyendo al jefe de la Marina, Emilio Massera, promovían una política exterior más hostil tanto frente a la administración Carter ${ }^{6}$ como frente a países vecinos como Chile, con quienes la Argentina mantenía abiertos litigios por cuestiones limítrofes.

De todos modos, el período de la transición a la administración Carter encontró a todas las facciones militares de la Argentina unidas en un cerrado apoyo a la estrategia de continuar con la represión ilegal sin dar lugar a concesiones frente a las presiones

\footnotetext{
${ }^{4}$ Era un lugar relativamente común entre los observadores de la época diferenciar entre un sector supuestamente "moderado" del Ejército, liderado por los generales Jorge Rafael Videla y Roberto Viola, y un sector "duro" encabezado por comandantes de Cuerpo como los generales Luciano Benjamín Menéndez y Guillermo Suárez Mason. Al respecto ver Novaro y Palermo (2003) y Avenburg (2015a).

${ }^{5}$ Risse y Sikkink (2007: 25-28) describen un espiral de cambio por el cual potencias extranjeras y activistas transnacionales presionan a gobiernos represivos para que garanticen los derechos de sus ciudadanos. Según ellos, una de las primeras reacciones de dichos gobiernos es la de adoptar "concesiones tácticas", medidas muy limitadas en material de Derechos Humanos que buscan aplacar la presión internacional sin imponer un verdadero cambio.

${ }^{6}$ Cabe destacar que Massera, en la búsqueda de apoyos de diversos actores para promover su propio liderazgo dentro de la Junta, alternaría posiciones más duras frente a los Estados Unidos (buscando el apoyo de los sectores "duros" del Ejército) con posiciones más conciliadoras con ese país. Massera llegando incluso a proponerse como un lider que garantizaría un mayor respeto a los Derechos Humanos frente a la supuesta debilidad de Videla (al respecto ver Avenburg, 2015b).
} 
norteamericanas. Luego del apoyo que había recibido en dos ocasiones el canciller argentino César Guzzetti de parte del secretario de Estado Henry Kissinger a mediados de $1976^{7}$, la Junta Militar aún se mostraba confiada en que la represión ilegal no sería un problema, al menos en el corto plazo, en sus relaciones con los Estados Unidos.

\section{La diplomacia silenciosa y los contactos bilaterales}

Una de las típicas estrategias adoptadas por funcionarios del ARA para prevenir sanciones a dictaduras aliadas fue la de argumentar, en sus informes internos, que el país en cuestión era de vital importancia para los intereses estratégicos de los Estados Unidos (Griesgraber, 1983, p. 155). Tal como puede verse en los informes de funcionarios del ARA de fines de 1976, el caso argentino no fue una excepción. En diciembre de 1976 aún en tiempos de la administración de Gerald Ford - Fernando Rondon, oficial para la Argentina del ARA, hacía un informe sobre las relaciones entre los Estados Unidos y la Argentina destacando el interés que tenía este país para los Estados Unidos. Rondon, así como gran parte de los funcionarios del ARA, era partidario de una diplomacia silenciosa. De acuerdo con su informe, la Argentina no era un país de gran importancia desde el punto de vista comercial, ya que el tamaño del comercio bilateral no era muy importante, ni desde el punto de vista de las inversiones norteamericanas. El interés de Estados Unidos, según el funcionario, se debía a que la Argentina estaba alcanzando un estatus de poder medio, por tener un importante grado de avance en su desarrollo nuclear, por ser un gran exportador de carne y cereales, lo cual tendría un lugar de suma importancia en un mundo de escasez de alimentos, y por la calidad de sus recursos humanos (SADP, "US-Argentine Relations", 9/12/76). En el análisis de Rondon no sólo se tomaba en cuenta la importancia estratégica que tenía la Argentina, también se reconocían dilemas propios de la política de Derechos Humanos: la posibilidad de que la presión fuera contraproducente. Rondon destacaba el riesgo de que una reducción en la asistencia militar empeorara la represión generando reacciones nacionalistas por parte de los militares. Por eso, afirmaba Rondon, los diplomáticos norteamericanos debían evitar condenar públicamente al gobierno y ejercer abiertamente presiones al presidente Videla, a quien consideraban un moderado ${ }^{8}$ (SADP, "US-Argentine Relations", 9/12/76).

A pesar de su postura favorable a la diplomacia silenciosa, los funcionarios del ARA se preocuparon por dejar en claro la seriedad de la política de Derechos Humanos. Aún aquellos que creían que era un error afectar las relaciones con un aliado, sabían que era necesario que los argentinos comprendieran el mensaje desde el principio para evitar que las sanciones los tomaran por sorpresa. En diciembre de 1976 el subsecretario del ARA Charles Bray visitó la Argentina y se reunió entre otros con el ministro del Interior, Albano Harguindeguy. En su reunión con el ministro, Bray insistió que la nueva política era un interés genuino de los Estados Unidos y no una acción de grupos minoritarios, y

\footnotetext{
${ }^{7}$ Respecto al apoyo de Kissinger a la Junta Militar ver Sikkink (2004a).

${ }^{8}$ La idea de que Videla era un moderado y que su deseo era limitar o acabar con la represión ilegal era una idea muy presente en los análisis de la diplomacia norteamericana. La imagen consistía en que Videla era un moderado a quien se opondrían los militares de línea dura como el general Guillermo Suárez Mason y el general Luciano Benjamín Menéndez. Ver al respecto Avenburg (2015).
} 
que la Argentina debía asumirlo como tal; y le aconsejó que ante sucesos como la visita de algún congresista norteamericano - en aquél momento se discutía la posibilidad de que el senador demócrata Donald Fraser visitara la Argentina - o declaraciones de testigos representando al gobierno argentino en la audiencia que se estaba desarrollando en el Congreso norteamericano, el gobierno argentino debía estar bien preparado para el tipo de preguntas que típicamente se les haría. Por ejemplo, explicó, mostrando evidencias de condenas a miembros de las fuerzas de seguridad responsables de abusos. Harguindeguy le respondió que aún en una guerra limpia, declarada y peleada entre dos ejércitos con uniforme, había individuos que cometían excesos, y que en una guerra sucia como la que estaba peleando el Ejército argentino las posibilidades de que hubiera excesos era mucho mayor. El norteamericano también le insistió en que publicaran las listas de detenidos. El argentino le prometió que se publicarían periódicamente listas en las que se informaría cuántos ciudadanos habían sido detenidos y cuántos liberados. Sin embargo, ese mismo día al mediodía, Bray se había reunido con José Villarreal, el general que encabezaba la Secretaría General de la Presidencia, quien le había asegurado que por razones de seguridad no se publicaría ninguna lista (SADP, "Conversation with Argentine Interior Minister", 9/12/76).

A diferencia del período anterior a la victoria de Carter, en el que los norteamericanos enviaron señales contradictorias (Sikkink, 2004b), en este período hubo un mensaje unívoco. Bray no simpatizaba con la política de Derechos Humanos, sin embargo, era consciente de que sin cambios por parte de los argentinos las sanciones se impondrían en el futuro.

A finales de diciembre de 1976, el Departamento de Estado comenzó a diseñar sus objetivos hacia la Argentina de acuerdo a la política de la nueva administración. Estos objetivos consistían en una serie de pasos o medidas que sería deseable que el gobierno argentino llevara a cabo, ordenadas por orden de preferencia. Las consideradas preferibles eran la publicación de un listado de todos los detenidos, que todos los detenidos tuvieran la posibilidad de acceder a un abogado y ser visitado por los familiares, perseguir y castigar a los extremistas de derecha y de izquierda que hubieran violado la ley, reconocer y aplicar el artículo 3 de la Convención de Ginebra de 1949 para conflictos internos, investigar los casos de abusos por parte de personal de seguridad a cargo de las detenciones y la custodia de detenidos y juzgarlos y condenarlos (SADP, s/t, 27/12/76).

De acuerdo con estos objetivos, los oficiales del Departamento de Estado James Buchanan de la Oficina de Inteligencia e Investigaciones del Departamento de Estado y F. Armstrong del ARA enviaron una seria de instrucciones a los funcionarios de la Embajada explicando cómo plantear estas medidas ante el gobierno argentino (SADP, s/t, 4/1/77). Recomendaban enfatizar que cada uno de los puntos fortalecerían a la Argentina y debilitarían a sus críticos y evitar un tono paternalista en las conversaciones. Con respecto a la publicación de las listas de detenidos, se afirmaba que dado que el gobierno argentino ya estaba publicando algunas listas, sería necesario mostrar satisfacción por este hecho y a la vez expresar que sería deseable que se publiquen las listas de todas las personas que se detenían al momento de ser detenidas, y no con posterioridad. Con respecto a la regularización de los procedimientos de detención, se sugería argumentar que dado que en todos los casos de detenciones había suficiente material probatorio para inculpar a los acusados, se podía juzgar los casos en procedimientos públicos bajo cortes civiles utilizando las leyes de seguridad nacional, y que realizar los juicios en cortes militares sin garantías legales no hacía más que enajenar posibles apoyos al régimen y aumentar la 
polarización. Con respecto a castigar los abusos cometidos por las fuerzas de seguridad, se recordaba que a menudo los miembros del gobierno aducían que tales medidas desmoralizarían a estas fuerzas en su combate a las guerrillas. Sin embargo, continuaba el informe, ahora había un cierto grado de consenso dentro de las Fuerzas Armadas de que estas organizaciones estaban perdiendo poder, por lo que se podía aducir que en estas circunstancias ya no era excusable seguir alentando estas conductas (SADP, s/t, 4/1/77).

Testimonios orales ilustran mejor la posición del ARA respecto de la política de Carter. Según el diplomático retirado Tex Harris, el ARA se oponía a esta política ya que creían que dañaría las relaciones entre la Argentina y los Estados Unidos, relaciones que ellos venían cultivando desde hacía años. Su problema era cómo satisfacer a la Casa Blanca pero "sin darles demasiado" (entrevista a Tex Harris, AHO).

\section{Las disputas en torno a la posibilidad de sanciones}

En enero de ese año - luego de la asunción de Carter - comenzó a discutirse la conveniencia o no de aplicar la Sección 502B a la Argentina reduciendo el monto de asistencia militar planeado para el año fiscal 1977. La administración Ford había solicitado una suma de 32 millones de dólares para la Argentina. Esta sería la primera ocasión en que la nueva administración debería decidir si sancionar o no a la Argentina por su conducta. La opinión del Departamento de Estado era que debía mantenerse la asistencia militar a la Argentina de acuerdo a lo presupuestado, es decir, no era conveniente sancionar a la Argentina. En un informe de comienzos de enero de 1977 exponía sus razones, basadas principalmente en dos argumentos. El primero de los argumentos era que la asistencia militar que los Estados Unidos proveían a la Argentina no estaba destinada a la "lucha contraterrorista". En ese sentido, se afirmaba que la única asistencia militar de los Estados Unidos era para combatir el narcotráfico y que los créditos militares de los Estados Unidos se otorgaban casi exclusivamente para grandes inversiones, como barcos y aviación y por ende tenían poca o ninguna aplicación en armas y equipamiento destinados a la "lucha contraterrorista" (SADP, "Argentina", 1/77).

El segundo de los argumentos refería a la importancia de la Argentina como actor estratégico y a la importancia de mantener un canal de influencia sobre un factor de poder en la Argentina como eran los militares. En ese sentido, se destacaba la importancia estratégica de la Argentina como un país de importantes dimensiones con acceso al Atlántico Sur y como un poder medio en términos de desarrollo, con un importante grado de industrialización, planes ambiciosos de desarrollo nuclear, siendo también uno de los principales exportadores de productos alimenticios. Se afirmaba que la asistencia militar daba a los Estados Unidos acceso a los militares argentinos que siempre fueron un actor importante y que también les daba a los militares argentinos un mayor interés por mantener buenas relaciones con los Estados Unidos, lo que ayudaba a proteger y promover los intereses norteamericanos. El informe concluía dejando en claro la posición del ARA:

Para poder preservar una relación profesional con las Fuerzas Armadas argentinas y demostrar que tenemos interés en relaciones constructivas con la Argentina, promoviendo los objetivos políticos señalados arriba, el Departamento de Estado tiene la opinión de que es en el interés na- 
cional de los Estados Unidos proveer continua asistencia militar a la Argentina (SADP, “Argentina", 1/77, traducción propia).

Vemos a través de este cable las razones por las cuales el Departamento de Estado se oponía a la política de sanciones. Por un lado, se repetía el argumento de la importancia de la Argentina para la seguridad de Estados Unidos: la extensión de sus costas en el Atlántico, su desarrollo nuclear y sus recursos alimentarios. Por el otro, el Departamento se mostraba reacio a abandonar su tradicional política de buscar acercarse a los militares para influir sobre el país. Ésta había sido la tradicional política del ARA. Su perspectiva era que había en América Latina dos instituciones estables: la Iglesia Católica y las Fuerzas Armadas. Dado que era imposible influir sobre la Iglesia Católica, el ARA se había concentrado en cultivar buenas relaciones con los militares (entrevista a Tex Harris, AHO). La asistencia militar tenía principalmente ese objetivo (Schoultz, 1981). Ambos argumentos - la importancia de la Argentina y la conveniencia de influir sobre los militares - se orientarían hacia una oposición a la política de Derechos Humanos, en la medida en que ésta suponía un conflicto con el gobierno militar. Se tradujeron, como vimos, en una oposición a la aplicación de la Enmienda 502B al caso argentino. Sin embargo, no parecen haberse traducido en un mensaje de menor compromiso con los Derechos Humanos en las conversaciones con las autoridades argentinas.

\section{La diplomacia silenciosa y el cambio de administración}

En las vísperas del cambio de administración, los funcionarios de la administración saliente se preocuparon por dejar en claro a los argentinos el importante lugar que los Derechos Humanos tendrían en el futuro y la necesidad de cambios por parte de la Argentina para seguir recibiendo el apoyo de los Estados Unidos. El 11 de enero, se reunieron en Washington el embajador de la Argentina Jorge Aja Espil, el agregado militar Luis María Miró junto con dos oficiales del ARA, Robert Zimmerman y Charles Bray y con el general norteamericano Richard Cavazos. Los funcionarios del ARA expresaron su visión sobre la política de la nueva administración; su visión muestra una posición de desacuerdo pero, reconociendo que no se podía evitar que esta política dominara, se buscaba que ella no dañara las relaciones entre los dos países hasta un punto de no retorno.

Bray trató de explicar la nueva orientación como un vuelco hacia la moral tradicional de la clase media, emparentada con el interés del Congreso, de grupos religiosos y de la ciudadanía en general en los Derechos Humanos. El funcionario dijo que esperaba que el nuevo cuadro no generara una tensión entre los dos países y que estaban haciendo todo lo posible para evitarlo, pero que para ello se necesitaban cambios de parte de la Argentina. Nuevamente solicitó que el gobierno argentino publicara las listas de los detenidos y castigara a los responsables de violaciones a los Derechos Humanos. Bray agregó que recientemente Estados Unidos había aprobado créditos por 8 millones de dólares para la compra de repuestos gracias a su esfuerzo y al de otras personas en la administración, pero que no había sido fácil por la fuerte oposición que habían tenido. Y advirtió que en el futuro, solo se podrá aprobar nuevos créditos si el gobierno argentino impulsa alguna de las medidas solicitadas (SADP, "Discussion on Human Rights Issue with Ambassador Aja Espil and General Miro", 11/1/77). 
Al día siguiente, el general Cavazos llamó a Miró, quien ya se había comunicado con Roberto Viola reportando la conversación. Cavazos le planteó a Miró la necesidad de la colaboración argentina para evitar el deterioro de las relaciones, y le repitió las dos medidas que necesitaban para poder seguir apoyando a la Argentina en sus solicitudes de créditos (SADP, "Discussion on Human Rights Issue with Ambassador Aja Espil and General Miro", 11/1/77).

Poco tiempo después de la asunción de Carter, el 20 de enero de 1977, la Embajada de Estados Unidos en Buenos Aires recibió instrucciones de Washington. Se le requería, entre otras cosas, seguir de cerca la situación de los Derechos Humanos, reportando los efectos de las sanciones y aconsejando modificaciones en respuesta a cambiantes circunstancias; inquirir ante las autoridades argentinas sobre casos individuales; mantener relaciones cercanas con organismos de Derechos Humanos locales y con la Iglesia y alentar a otras misiones diplomáticas a involucrarse en el tema; mantener un diálogo con los partidos políticos y líderes sindicales y alentarlos a que presenten medidas constructivas para el retorno de la democracia (SADP, "Goals Implementation - Argentina", s/f).

A comienzos de febrero de ese año, ante la pronta decisión en Washington sobre el monto de asistencia militar que se otorgaría a la Argentina, funcionarios del ARA intentaron persuadir a las autoridades argentinas de que publicaran las listas y castigaran a represores, para poder así evitar sanciones vía reducción de la asistencia militar. Los funcionarios sabían que necesitaban cambios por parte de la Argentina para que hubiera algún argumento a favor del mantenimiento de la asistencia militar. En ocasión de un viaje a Buenos Aires del embajador argentino Jorge Aja Espil, el funcionario del ARA Fernando Rondon se comunicó con el consejero político de la Embajada argentina Víctor Beauge y dos días más tarde con el primer secretario de la Embajada Urrutia para conversar sobre la asistencia militar a la Argentina para el año 1977. Rondon había sido autorizado a mantener esas conversaciones con el objetivo de que Aja Espil en su estadía en Buenos Aires las transmitiera a las autoridades argentinas. En su conversación con Beauge, Rondon le dijo que no desean ver un deterioro de las relaciones entre los dos países a causa de los Derechos Humanos, y le recordó las dos medidas que el subsecretario Bray había aconsejado que adoptaran las autoridades argentinas. Además, le dijo que sería deseable que el gobierno operara dentro del marco de la ley y que las detenciones fueran públicas, y que permitieran una visita de la Comisión Interamericana de Derechos Humanos o de la Comisión de Derechos Humanos de la ONU (SADP, "US-Argentine Relations", 2/2/77). Rondon concluyó el encuentro diciendo que las relaciones entre los dos países estaban en un punto de inflexión y que el destino de ellas dependía únicamente de los argentinos (SADP, "US-Argentine Relations", 2/2/77).

Durante la estadía en Buenos Aires de Aja Espil, el embajador norteamericano Robert Hill le pidió una reunión pero éste adujo tener la agenda ocupada. Sin embargo, Hill recibió comentarios de una fuente ligada a la Embajada, que se había reunido con Aja Espil y con el canciller César Guzzetti, y aseguraba que Aja Espil estaba de acuerdo con que la Argentina tomara una de las dos medidas pedidas por los Estados Unidos pero Guzzetti se oponía rotundamente, con el argumento de que publicar las listas no haría más que favorecer a la "subversión" y que castigar al personal de las fuerzas de seguridad no haría más que desmoralizarlas. Según la misma fuente, mientras que Aja Espil estaba convencido de que el no tomar medidas llevaría a una confrontación con los Estados 
Unidos, Guzzetti sostenía que esas medidas eran inaceptables (SADP, "US-Argentine Relations", 3/2/77).

Hill concluiría que no era mucho lo que los Estados Unidos podrían hacer y así lo comunicaría al Departamento de Estado. Este general republicano se opuso a la política de sanciones por considerarla contraproducente y siempre se pronunció con escepticismo sobre la posibilidad de que el gobierno de Videla detuviera la represión ilegal. Pero no por eso puede considerarse que no estuviera comprometido con el progreso de los Derechos Humanos en la Argentina. Sus intentos de convencer a los argentinos de que Estados Unidos no ampararía sus prácticas y sus discusiones con el secretario de Estado Henry Kissinger por su oposición a dar mensajes ambiguos o contradictorios a los argentinos han sido documentados en estudios previos (para este tema ver Sikkink, 2004a; Sikkink, 2004b, Schmidli, 2011).

A días de la decisión del Congreso, el embajador se comunicó telefónicamente con Guzzetti para hacer un último pedido para que el gobierno argentino enviara una señal positiva a los legisladores, pero el Canciller le reiteró que las dos medidas solicitadas eran inaceptables (SADP, "Call on Foreign Minister to Discuss Situation on Human Rights", 11/2/77).

Paralelamente, Wayne Smith, consejero político de la Embajada de Estados Unidos en Buenos Aires, envió un reporte al Departamento de Estado informando sobre la actualidad política en la Argentina y argumentando en contra de la política de sanciones. En dicho informe, Smith destacaba la necesidad de mantener buenas relaciones con la Argentina dado el importante rol que podía tener el país para un orden mundial más estable, y por su importante potencial en términos de desarrollo nuclear. Smith argumentaba a favor de una diplomacia silenciosa, ya que, según él, una confrontación abierta podría generar una reacción nacionalista en la Argentina, exacerbando la represión (SADP, “Argentine Overview", 28/1/77).

Ninguno los esfuerzos de estos funcionarios dio resultados. A finales de febrero de ese año, el secretario de Estado de la nueva administración, Cyrus Vance, anunció que, de los 32 millones presupuestados para asistencia militar en la administración Ford se otorgarían solamente 15 millones, declarando públicamente que la reducción se debía a las violaciones a los Derechos Humanos del régimen de Videla. La reacción por parte del gobierno argentino fue rechazar toda la asistencia, declarando que se estaba interfiriendo en los asuntos domésticos de la Argentina. Se iniciaba así un período de fuertes sanciones de parte de la administración Carter.

Poco tiempo después, el 17 de marzo, la Embajada envió un reporte evaluando la recepción de los distintos sectores de la sociedad argentina a las sanciones impuestas por Estados Unidos. El cable estaba firmado por el consejero político de la Embajada, Anthony Freeman, y por el embajador Hill. Informaban que los principales miembros del gobierno argentino no comprendían las acciones de los Estados Unidos, y que estaban "desilusionados y enojados" ya que creían que mientras luchaban por su propia supervivencia, estaban defendiendo los valores occidentales y por lo tanto los intereses de Estados Unidos, y se sentían ofendidos por la facilidad con que se los sancionaba, junto a países como Etiopía, mientras que otros países como Filipinas y Corea del Sur recibían otro trato (SADP, “Argentine Reactions to Human Rights Issues", 17/03/77).

En el cable ambos funcionarios se mostraban abiertamente críticos de la política de sanciones, señalando que difícilmente la presión externa podría influir en la conducta de 
los argentinos, y que en el mejor de los casos podrían realizar algunos cambios cosméticos para atenuar las críticas internacionales. Y argumentaban que, de acuerdo a las opiniones recogidas entre los militares de mayor graduación de las tres fuerzas, la reducción de la asistencia militar no traerá ningún efecto positivo en las "tácticas contraterroristas" utilizadas por el gobierno argentino. Por eso abogaban por un enfoque alternativo para llevar a cabo esta política, un enfoque que no estuviera basado en la política de sanciones. El embajador Hill volvió a enviar un cable a Washington en abril de 1977, criticando la política de sanciones, argumentando que le resultaba claro que el gobierno argentino estaba decidido a continuar su lucha contra la subversión con o sin el apoyo de los Estados Unidos (State, "Visit to Argentina of LTG Gordon Sumner, Chairman, Inter American Defense Board (IADB)", 11/4/77). Esa posición, sin embargo, no fue atendida, y poco tiempo después Hill dejó su puesto como embajador en la Argentina.

La administración Carter continuaría con su política de sanciones, a pesar de las críticas de importantes sectores del Departamento de Estado. Esto no implicó, sin embargo, que el período de transición a la política de Derechos Humanos de Carter estuviese marcado por las "señales contradictorias". Al contrario, aún aquellos sectores más renuentes a adoptar dicha política, tuvieron en sus contactos bilaterales en privado un claro mensaje frente al gobierno argentino, buscando cambios puntuales que permitieran al ARA tener argumentos para frenar la política de sanciones a la Argentina.

\section{La administración Carter y los nuevos actores}

Con la llegada de Carter al poder, la Oficina de Derechos Humanos cobraría un peso mucho más significativo en las decisiones de política exterior. Una ex-activista del Movimiento por los Derechos Civiles en Mississippi, Patricia Derian, ocuparía el cargo de coordinadora de Derechos Humanos. Poco tiempo después, a mediados de 1977, el cargo sería elevado por decisión del Congreso al de secretario asistente de Derechos Humanos por lo que respondería directamente al secretario de Estado (Schoultz, 1981, p. 126).

Derian así tomaría un rol muy importante en las decisiones de política exterior hacia las dictaduras latinoamericanas. Con una postura contraria a la diplomacia silenciosa, impulsaría la implementación de sanciones militares y económicas a la Argentina, combinadas con fuertes críticas públicas a la dictadura militar. La llegada de Derian terminaría de sepultar la posibilidad de que las presiones norteamericanas se hicieran en contactos privados. Las sanciones y críticas públicas se transformaron así en el principal instrumento de la política de Washington hacia la Argentina. Al recorte en el monto para la asistencia militar anunciado por Vance se sumaron nuevas sanciones. En los primeros dos años de la administración, los delegados norteamericanos en instituciones financieras internacionales como el BID y el Banco Mundial votaron en contra o se abstuvieron en la mayoría de las solicitudes de crédito de la Argentina (Avenburg, 2009a).

A su vez, los conflictos inter-burocráticos se acentuaron, lo que llevó a la administración a crear el Comité Inter-Agencias de Derechos Humanos y Asistencia Externa, conocido en la jerga diplomática como el Christopher Committe, ya que su director era el secretario de Estado Adjunto, Warren Christopher, el segundo cargo en jerarquía dentro del Departamento de Estado. Dicho comité se encargaría de determinar, caso por caso, si correspondía sancionar por medio de reducciones a la asistencia económica o militar, 
habilitar o no la venta de determinado equipamiento militar o apoyar las solicitudes de crédito en instituciones financieras internacionales. Dada la gravitación de Derian y de HA dentro de la administración Carter, su postura terminó predominando en las decisiones de los primeros años de la administración Carter (Griesgraber, 1983).

A partir de mediados de 1977 los sectores del ARA y de HA comenzaron a confluir en una salida aceptable para ambos, consistente en presionar al gobierno militar argentino para que aceptara una inspección in situ de la Comisión Interamericana de Derechos Humanos (CIDH). Para HA se trataba de una oportunidad de que un organismo independiente y de buena reputación diera un testimonio objetivo y documentado de los abusos que venían denunciando los organismos de Derechos Humanos locales, mientras que para los funcionarios del ARA la posibilidad de una visita de un organismo Inter-americano significaba que ya no serían los Estados Unidos, unilateralmente, quienes pagarían los costos de las denuncias públicas (al respecto ver Novaro y Avenburg, 2009). De este modo, la visita de la CIDH se presentaría, finalmente, como un único punto de confluencia entre ambos sectores. El gobierno argentino, luego de cerca de un año y medio de negociaciones con la diplomacia norteamericana, aceptaría una inspección de la CIDH: la administración Carter había utilizado como arma de negociación la promesa de destrabar una garantía del Eximbank para un crédito que otorgarían la compañía norteamericana Allis Chalmers para construir turbinas hidroeléctricas destinadas a la represa de Yacyretá (Novaro y Avenburg, 2009).

Los funcionarios del ARA continuarían, durante este período, manteniendo contactos bilaterales con el gobierno argentino. En dichos contactos, continuarían enfatizando la necesidad de que el gobierno argentino termine con la represión ilegal y comenzara la normalización de los procedimientos. Al mismo tiempo, en algunas ocasiones, funcionarios del ARA manifestarían públicamente sus diferencias con la política de sanciones ${ }^{9}$.

La respuesta del gobierno argentino se manifestó, en los diálogos con los funcionarios norteamericanos, alternando argumentos sobre la necesidad de terminar con la subversión con justificaciones sobre el rol moderador del presidente Videla y sus dificultades para limitar el accionar de grupos para-militares que supuestamente operaban sin su consentimiento (Avenburg, 2015a). Paralelamente, los sectores "duros" del Ejército y la Marina manifestarían su oposición y rechazo frente a la "intromisión externa" y la "traición" de los Estados Unidos al haber dejado de lado su compromiso con la defensa del continente frente al comunismo.

En términos de medidas concretas, la respuesta a las presiones fue claramente muy limitada: el gobierno militar continuaría ejerciendo la represión ilegal a gran escala hasta finales del año 1979 y, a partir de la visita de la CIDH, la misma continuaría aunque en menor escala. El gobierno argentino comenzaría a publicar periódicamente las listas de detenidos bajo la autoridad del Poder Ejecutivo Nacional a partir de fines de 1977, intentando satisfacer las demandas de la diplomacia norteamericana sin resignar su estrategia

\footnotetext{
${ }^{9}$ Por ejemplo, a comienzos de 1978 el subsecretario de Asuntos Latinoamericanos Terence Todman, quien había sido seleccionado para el cargo durante los inicios de la administración Carter, declaró en un charla en el Centro para las Relaciones Interamericanas en Nueva York que uno de los "diez errores tácticos" que el gobierno norteamericano debía evitar era el de "condenar a todo un gobierno por cada acto negativo cometido por alguno de sus miembros" (citado en Schoultz 1981: 118, traducción propia). Poco tiempo después la administración decidió removerlo del cargo.
} 
de represión ilegal (Avenburg, 2015a). A su vez, Videla buscaría aplacar las presiones norteamericanas presionando a los sectores "duros" del Ejército para lograr la liberación de detenidos-desaparecidos por los que había una fuerte presión internacional, como en el caso del periodista y director del diario La Opinión, Jacobo Timerman, del sindicalista docente y miembro de la Asamblea Permanente por los Derechos Humanos, Alfredo Bravo, y de los integrantes de la familia Deustch en Córdoba (Avenburg, 2015a).

\section{Conclusiones}

En los cables analizados hemos visto que todas las opiniones de los funcionarios y diplomáticos del ARA y de la Embajada eran contrarias a la política de sanciones a la Argentina, recomendando en su lugar la diplomacia silenciosa. Esta opción era defendida por medio de dos argumentos. En primer lugar, se consideraba que la confrontación sería contraproducente porque sólo serviría para acrecentar el poder de los militares de línea dura y para generar reacciones nacionalistas. En segundo lugar, se destacaba la importancia de la Argentina y la inconveniencia de poner en riesgo las relaciones con este país aliado.

En algunos casos, podemos ver que la oposición a la política de sanciones era en realidad una oposición a la política de Derechos Humanos en sí misma, como en el caso del subsecretario Charles Bray. En otros casos, la oposición a la política de sanciones no implicaba que no pudiese haber una defensa sincera de los Derechos Humanos a través de la diplomacia silenciosa. Esto lo vemos en el caso del embajador Hill, quien se opuso a la reducción de la asistencia militar sin dejar de tener una postura muy crítica de las prácticas del gobierno argentino (Sikkink, 2004a; Schmidli, 2011). En este sentido, la ejecución de la política de Derechos Humanos era conflictiva no sólo porque muchos funcionarios se oponían a su misma existencia, sino también porque aún entre quienes la apoyaban había diferencias sobre varios puntos: cómo combinar "garrotes" y "zanahorias", hasta dónde preservar un buen entendimiento y en qué medida éste era necesario para poder influir sobre las prácticas del gobierno argentino. Estos sectores podían acordar que había que detener las violaciones a los Derechos Humanos, lo que no implicaba que acordaran cómo hacerlo.

Los funcionarios del ARA menos comprometidos con la política de Carter, como Bray, veían que para que los Derechos Humanos no fueran un problema para las relaciones bilaterales necesitaban algún cambio por parte del gobierno argentino. Se encontraban entre una administración que pedía un fuerte cambio por parte de la Argentina, y un gobierno argentino que no quería ceder en nada. Su tarea requería de encontrar un acercamiento entre ambas posiciones, pero no podían hacer esto sin obtener alguna medida concreta de parte de la Argentina. Comprendieron que su objetivo, mantener relaciones estrechas, no podía cumplirse por otro medio que enviando un claro mensaje a sus interlocutores argentinos de la importancia que tenía para la administración norteamericana el respeto a los Derechos Humanos.

De este modo, los objetivos de la nueva administración se transformaron en un medio para ellos. En la medida que los instrumentos para ejercer presión sobre la Argentina - en este caso la reducción de la asistencia militar - pasaban por decisiones del Congreso y de la Casa Blanca sobre las cuales el ARA tenía una incidencia limitada, los funcionarios más conciliadores se encontraron en la posición de ser rehenes de las decisio- 
nes de aquellos actores, no pudiendo asumir otro rol que el de impulsar los objetivos de la nueva administración, aunque fuera como medio para perseguir sus objetivos tradicionales. Encontramos que, a diferencia de los estudios que destacan el poder de la burocracia en la determinación de las políticas, en este caso ante el disenso con una política, los funcionarios no hacen otra cosa que impulsarla, de modo que el resultado que pudieron percibir las autoridades argentinas fue de un impulso de toda la diplomacia norteamericana a los Derechos Humanos.

De este modo, la preferencia de los funcionarios del ARA por la diplomacia silenciosa no significó que la burocracia impidiera una efectiva implementación de una política de Derechos Humanos basada en sanciones, en la medida en que, en los debates internos, la administración Carter tendió a privilegiar la posición de HA, al menos durante este primer período. Del mismo modo, sus argumentos de que la Argentina era un socio estratégico vital para los Estados Unidos, por lo cual ameritaba hacer del caso una excepción en la política de sanciones, resultaron poco convincente para la nueva administración. En suma, si bien los documentos analizados no permiten afirmar que hubo en el ARA una defensa sincera de la orientación planteada por la administración Carter, sí podemos afirmar que, dada su posición de relativa debilidad en el esquema de poder intra-burocrático planteado por la nueva administración, estos actores no generaron un verdadero obstáculo en la implementación de dichos objetivos. Más bien, en sus contactos bilaterales con el gobierno argentino, se empeñaron en lograr algunos cambios, aunque fueran limitados, en la dirección deseada por la Casa Blanca.

\section{Referencias bibliográficas}

-Allison, Graham y Philip Zelikow (1999): Essence of Decision. Explaining the Cuban Missile Crisis, segunda edición, Estados Unidos: Addison Wesley Longman.

-Apodoca, Clair (2005): "U.S. Human Rights Policy and Foreign Assistance: A Short Story", Ritsumeikan International Affairs, Tokio, v. 3, pp. 63-80.

-Arnson, Cynthia J. (1993): Crossroads. Congress, the President, and Central America, 19761993, Pennsylvania: The Pennsylvania State University Press.

-Avenburg, Alejandro (2015a): “Entre la Presión y el Apoyo. La Política de Derechos Humanos de los Estados Unidos y el Gobierno Militar Argentino (1976-1978)", Desarrollo Económico, Buenos Aires, v. 55, n. 215, pp. 107-136.

-Avenburg, Alejandro (2015b): “Una Dictadura Fragmentada: Conflictos Intra-Militares y las Relaciones entre la Argentina y los Estados Unidos durante la Presidencia de Videla", PostData, Buenos Aires, v. 20, n. 2, pp. 441-471.

-Bosoer, Fabián (2005): Generales y Embajadores. Una Historia de las Diplomacias Paralelas en Argentina, Buenos Aires: Editorial Vergara.

-Cisneros, Andrés y Carlos Escudé (comps.) (2000): Historia General de las Relaciones Exteriores de la República Argentina. Tomo XIV. Las Relaciones Políticas, 1966-1989, Buenos Aires: Grupo Editor Latinoamericano.

-Da Vinha, Luis. (2014): “Revisiting the Carter Administration's Human Rights Policy: Under- 
standing Traditional Challenges for Contemporary Foreign Policy", Revista de Paz y Conflictos, Granada, no 7, pp. 99-122.

-Destler, I. M. (1974): Presidents, Bureaucrats, and Foreign Policy. The Politics of Organizational Reform, New Jersey: Princeton University Press.

-Escudé, Carlos (1991): “Argentina: The Costs of Contradiction”, en: Lowenthal, Abraham F. ed., Exporting democracy. The United States and Latin America. Case studies, Baltimore: The John Hopkins University Press, pp. 125-160.

-Forsythe, David (2012): Human Rights in International Relations. Third Edition, Nueva York: Cambridge University Press.

-Griesgraber, Jo Marie (1983): "Implementation by the Carter Administration of Human Rights Legislation Affecting Latin America." Ph.D. Dissertation, Georgetown University.

-Halperin, Morton H. y Priscilla A. Clapp (2007): Bureaucratic Politics and Foreign Policy, segunda edición, Washington DC: Brookings Institution Press.

-Novaro, Marcos y Alejandro Avenburg (2009): "La CIDH en la Argentina: Entre la Democratización y los Derechos Humanos”, Desarrollo Económico, v. 49, no 143, pp. 6190.

-Novaro, Marcos y Vicente Palermo (2003): La Dictadura Militar. 1976-1983. Del Golpe de Estado a la Restauración Democrática, Buenos Aires: Paidos.

-Risse, Thomas y Kathryn Sikkink (2007): “The Socialization of International Human Rights Norms into Domestic Practices: an Introduction", en Risse, Thomas y Kathryn Sikkink eds., The Power of Human Rights. International Norms and Domestic Change, New York: Cambridge University Press, pp. 1-38.

-Schmidli, William (2011): “Institutionalizing Human Rights in U.S. Foreign Policy: U.S.Argentine Relations, 1976-1980", Diplomatic History, Malden, MA, v. 35, no. 2, pp. 351-377.

-Schmitz, David F. y Vanessa Walker (2004): “Jimmy Carter and the Foreign Policy of Human Rights: The Development of a Post-Cold War Foreign Policy", Diplomatic History, Malden, MA, v. 28, no 1, pp. 113-143.

-Schoultz, Lars (1981): Human Rights and United States Policy toward Latin America, New Jersey: Princeton University Press.

-Sikkink, Kathryn y Lisa Martin (1993): "U.S. Policy and Human Rights in Argentina and Guatemala, 1973-1980”, en: Putnam, R., Evans, P. y Jacobson, H. K. eds.., DoubleEdged Diplomacy, California: University of California Press.

-Sikkink, Kathryn (2004a): “Kissinger y la Guerra Sucia: Un Análisis de los Documentos Desclasificados Recientemente", Revista Iberoamericana de Análisis Político, Año 1, Número 2, Diciembre de 2004, Buenos Aires: Fondo de Cultura Económica.

-Sikkink, Kathryn (2004b): Mixed Signals. U.S. Human Rights Policy and Latin America, Ithaca: Cornell University Press. 


\section{Fuentes:}

-Archivo de Historia Oral. Programa de Historia Política del Instituto de Investigaciones Gino Germani. Facultad de Ciencias Sociales. Universidad de Buenos Aires.

-State Argentina Declassification Project (1975-1984), disponible en sitio web: https:// foia.state.gov/Search/Search.aspx. 